\title{
Morphology of intervertebral disc ruptures evaluated by vacuum phenomenon using multi-detector computed tomography: association with lumbar disc degeneration and canal stenosis
}

Koichiro Murata ${ }^{1 \dagger}$, Koji $^{\text {Akeda }}{ }^{{ }^{*+}}$ (D), Norihiko Takegami ${ }^{1}$, Kevin $^{\text {Cheng }}{ }^{2}$, Koichi Masuda ${ }^{2}$ and Akihiro Sudo ${ }^{1}$

\begin{abstract}
Background: The progression of intervertebral disc (IVD) degeneration leads to rupture within IVD tissues. The location and appearance of areas of gaseous radiolucency in the IVD, known as vacuum phenomena (VPs), are considered to indirectly indicate the position and extent of IVD rupture. The clinical significance of VPs in degenerated IVDs is not fully understood. The purpose of this study is to assess and classify the morphology of IVD ruptures by the presence of intradiscal VPs, and to examine the association between morphological VP-positive IVD ruptures and degenerative lumbar diseases.

Methods: IVD rupture was evaluated by the presence of VPs using computed tomography (CT) imaging. VP shape (spot, linear, island) was classified using sagittal imaging, and VP distribution (A-N: anterior AF-NP; N: NP only; N-P: NP-posterior AF; A-N-P: anterior and posterior AF-NP) was classified using axial imaging. The disc height index (DHI) was calculated from lateral radiographs. Disc degeneration and lumbar spinal stenosis were evaluated by MRI grade.

Results: In the VP shape analysis, the island type was the most common, followed by linear and spot types. In the VP distribution analysis, A-N was the most common group, followed by N, N-P and A-N-P. Intra- and inter-observer reliabilities were statistically sufficient to classify different rupture shapes and distributions. The DHI tended to be lower in discs that contained VPs, especially in the anterior AF area. The shape and distribution of intradiscal VPs were significantly associated with the degree of disc degeneration and lumbar spinal stenosis graded by MRI. Discs with VPs extending from the NP into the anterior and/or posterior AF had a significantly higher proportion of advanced disc degeneration (Pfirrmann's classification: grades IV and V).

Conclusions: This is the first study to analyze the morphology of IVD rupture evaluated by the presence of intradiscal VPs using CT imaging. This classification can comprehensively present the shape and axial distribution of VPs within IVDs. Intradiscal VPs are associated with the progression of disc degeneration and lumbar spinal stenosis.
\end{abstract}

Keywords: Intervertebral disc, Intervertebral disc degeneration, Intervertebral disc vacuum phenomenon, Computed tomography, Lumbar spinal stenosis

\footnotetext{
* Correspondence: k_akeda@clin.medic.mie-u.ac.jp

${ }^{\dagger}$ Koichiro Murata and Koji Akeda contributed equally.

${ }^{1}$ Department of Orthopaedic Surgery, Mie University Graduate School of

Medicine, 2-174 Edobashi, Tsu City, Mie 514-8507, Japan

Full list of author information is available at the end of the article
}

(c) The Author(s). 2018 Open Access This article is distributed under the terms of the Creative Commons Attribution 4.0 International License (http://creativecommons.org/licenses/by/4.0/), which permits unrestricted use, distribution, and reproduction in any medium, provided you give appropriate credit to the original author(s) and the source, provide a link to the Creative Commons license, and indicate if changes were made. The Creative Commons Public Domain Dedication waiver (http://creativecommons.org/publicdomain/zero/1.0/) applies to the data made available in this article, unless otherwise stated. 


\section{Background}

The intervertebral disc (IVD) consists of an outer annulus fibrosus (AF), which is rich in collagens accounting for its tensile strength, and an inner nucleus pulposus (NP), which contains large proteoglycans that retain water to maintain the osmotic pressure required for resistance against loading by compression. IVD degeneration is biochemically characterized by decreases in proteoglycan and water content in the NP, as well as collagen degeneration in the AF. The progression of IVD degeneration is known to lead to ruptures (including tears and/or cleft formation) within IVD tissues $[1,2]$.

Several authors have reported the morphological features of IVD ruptures [1-3], and have suggested the possibility that disc ruptures may be related to low back pain and/or the pathogenesis of degenerative lumbar diseases. IVD vacuum phenomena (VPs) refer to the radiographic appearance of a lucency caused by the presence of gas, usually in the lumbar region; this is one of the characteristics of IVD degeneration [4]. The location and appearance of gas is considered to indirectly indicate the position and extent of rupture within the IVD. However, only a few studies have reported the clinical relevance of intradiscal VPs [5, 6]. There have been no reports evaluating the types and distribution of intradiscal VPs or the association of intradiscal VPs and disc degeneration and/or degenerative disc diseases. Although magnetic resonance imaging (MRI) plays an important role in evaluating IVD pathologies [7], including tissue degeneration, it is less accurate than computed tomography $(\mathrm{CT})$ for detecting VPs [8].

The purposes of this study were (1) to evaluate and classify the morphology of IVD rupture by the presence of VPs using multi-detector computed tomography (MDCT) imaging, and (2) to examine the association between morphological IVD rupture and radiological lumbar disc degeneration and canal stenosis.

\section{Methods \\ Subjects}

This IRB-approved retrospective study was conducted on spinal computed tomography (CT) images of 99 consecutive patients (48 men and 51 women) who underwent spinal surgery. The overall average age of the patients was 67.5 years-old (range, 23-90). A total of 590 discs from T12/L1 to L5/S1 were analyzed. The clinical diagnoses of the patients were as follows: 74 lumbar spinal stenosis (LSS), 15 lumbar disc herniation (LDH), 7 cervical spinal diseases, and 3 others (Table 1 ). Multi-detector CT (MDCT) (slice increment: $1.0 \mathrm{~mm}$, slice thickness: $1.0 \mathrm{~mm}$; Asteion TSX-021B, Toshiba Medical Systems Co., Otawara, Tochigi, Japan) was performed for all patients. Lateral lumbar spine radiography was also performed in 75 patients and magnetic
Table 1 Patient demography

\begin{tabular}{lll}
\hline Diagnosis & Subjects (male/female) & Average age \\
\hline LSS & $74(34 / 40)$ & $71.5(23-90)$ \\
LDH & $15(9 / 6)$ & $53.6(36-77)$ \\
Cervical diseases & $7(6 / 1)$ & $62(44-88)$ \\
Others & $3(2 / 1)$ & $61.3(50-67)$ \\
Total & $99(51 / 48)$ & $67.5(23-90)$ \\
\hline
\end{tabular}

Computed tomography (CT) images of 99 patients (51 men and 48 women) with spinal diseases were reviewed. The overall average age was 67.5 years-old (range: 23-90). The clinical diagnoses of the patients were 74 lumbar spinal stenosis (LSS), 15 lumbar disc herniation (LDH), 7 cervical spinal diseases, and 3 others

resonance imaging (MRI) in 74 patients. All radiological images were taken within three-months before surgery.

\section{Morphological classification of VPs}

Intradiscal VPs were evaluated by the presence of areas of gaseous radiolucency using MDCT imaging. The morphological classification of intradiscal VPs included two separate categories, VP shape and rupture distribution.

\section{VP shape}

VP shape was evaluated using mid-sagittal imaging (Fig. 1). VP shapes were categorized according to three classifications: spot, linear, and island. A spot-type VP was defined as a point-like VP less than $2 \mathrm{~mm}$ in diameter. A linear-type rupture was defined as a radiating VP whose width was less than $2 \mathrm{~mm}$. An island-type rupture was defined as a VP forming a wide cleft $(>2 \mathrm{~mm})$.

\section{VP distribution}

VP distribution was classified using mid-axial imaging of intervertebral space (Fig. 2). The IVD was divided into three areas: nucleus pulposus $(\mathrm{N})$, anterior annulus fibrosus (A), and posterior annulus fibrosus (P) on axial CT images of the disc. Using these divisions, the distribution of the intradiscal VPs was classified into four categories created by combinations of the three areas: 1) A-N indicates a VP in both the anterior annulus fibrosis and nucleus pulposus, 2) $\mathbf{N}$ indicates a VP in only the nucleus pulposus, 3) N-P indicates a VP in both the nucleus pulposus and the posterior annulus fibrosis, and 4) A-N-P indicates a VP in the anterior and posterior annulus fibrosus as well as the nucleus pulposus.

\section{Disc height index (DHI)}

Using lateral lumbar spine radiographs of each subject, anterior disc height $(H a)$, posterior disc height $(H p)$, superior disc depth $(D s)$ and inferior disc depth $(D i)$ were measured. Disc height was expressed as the DHI, which was calculated as: $[(H a+H p) /(D s+D i)] \times 100$ [9]. 

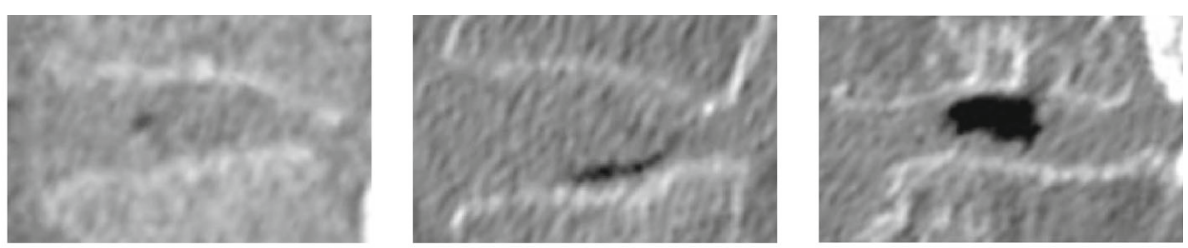

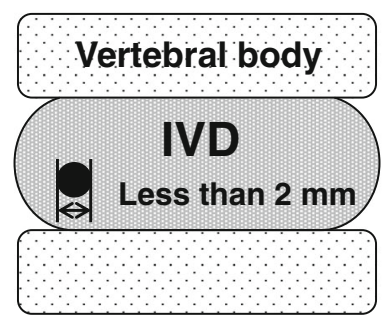

Spot

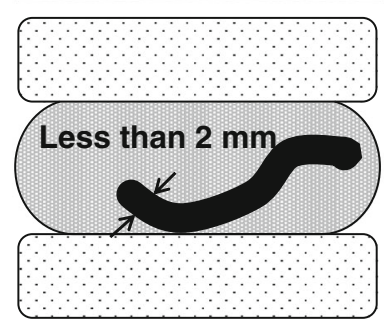

Linear

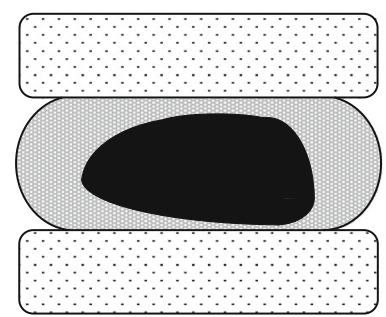

Island

Fig. 1 Shape type of vacuum phenomena. The presence of vacuum phenomena (VPs) was classified into three types (spot, linear, and island) using sagittal imaging by multi-detector computed tomography (MDCT)

\section{Classification of disc degeneration}

The degree of disc degeneration was evaluated by sagittal T2-weighted lumbar MRI, and was graded according to Pfirrmann's classification from Grades I to V [10]. Grades IV and V were defined as advanced stages of IVD degeneration.

\section{Classification of lumbar spinal stenosis (LSS)}

The extent of lumbar spinal stenosis was graded from A to $\mathrm{D}$ using the method based on the morphologic appearance of the dural sac (cerebrospinal fluid / rootlet ratio) on T2-weighted axial imaging [11]. Grades $\mathrm{C}$ and $\mathrm{D}$ were defined as severe stenosis.

\section{Data analysis}

Two observers (orthopaedic surgeons) assessed the CT classifications of VP shape and distribution. The reliability of the CT classifications using CT images from 55 randomly selected VP-positive discs (52 patients) was evaluated using agreement percentage and kappa statistics for both intra- and inter-observers [12]. The agreement was regarded as "substantial" when the kappa values were more than 0.61 [13].

\section{Statistical analysis}

Differences in the proportion of CT-classifications between males and females, and among age groups were statistically analyzed using the chi-square test or Fisher's

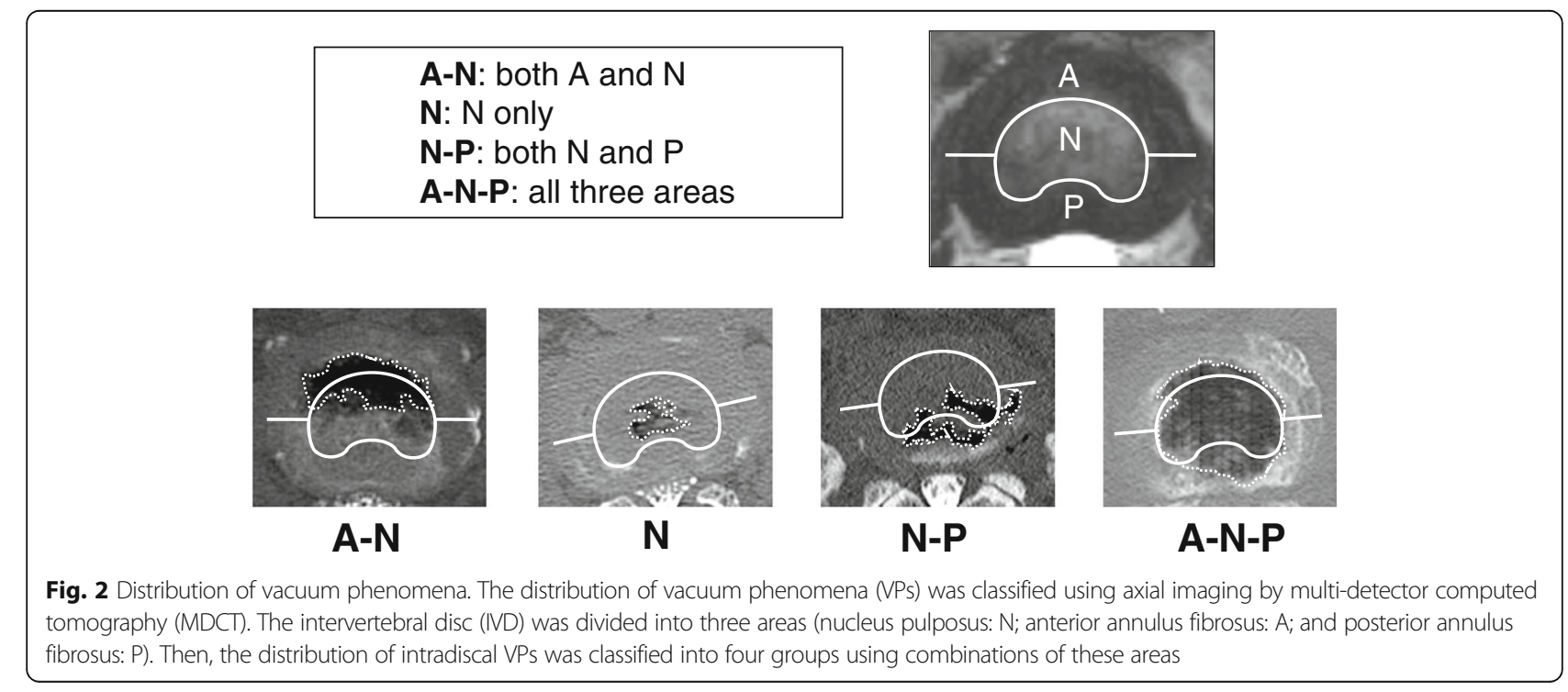


exact test. Statistically significant differences between the presence of VPs and DHI were assessed using one-way ANOVA followed by post hoc multiple comparisons using the Bonferroni method. The association between the morphology of ruptures (shape and distribution) and the MRI grading of disc degeneration or lumbar spinal stenosis was statistically assessed by the Fisher's exact test followed by a post hoc test. The post hoc test was performed to assess the probability values for each combination of independent category levels by using a Bonferroni correction to control for type I error inflation [14, 15]. All the statistical analyses were performed using IBM SPSS Statistics (IBM Japan, Tokyo or IBM Corp., Armonk, NY, USA).

\section{Results}

A VP was found in 226 discs (38.3\%) of the 590 discs analyzed. The number of VP-positive discs was highest in the L4/5 level and lowest in the T12/L1 level (n [\% of total VP-positive discs]: T12/L1: 19 [8.4\%]; L1/2: 34 [15.0\%]; L2/3: 40 [17.7\%]; L3/4: 36 [16.0\%]; L4/5: 54 [23.9\%]; L5/S1: 43 [19.0\%]) (Fig. 3a). The number of VPs was highest in the seventy (71-80 years-old) age group, followed by eighty, sixty, fifty and under fifty age groups (\% of total VP-positive discs: $21-50$ years-old: 3 [1.3\%], 51-60: 13 [5.8\%]; 61-70: 61 [27.0\%]; 71-80: 93 [41.6\%]; 81-90: 55 [24.3\%]) (Fig. 3b). The percentage of VP-positive discs by age group was highest in the eighty age group, followed by seventy, sixty, fifty and under fifty age groups (\% of VP-positive discs by age group: 21-50 years-old: $4.6 \%, 51-60: 21.7 \%$; $61-70$ : $35.7 \%$; 71-80: 46.1\%; 81-90: 61.1\%).
Intra- and inter-observer agreement of VP shape type Intra- and inter-observer agreement of the VP shape type was "substantial" with kappa values $0.75-0.76$ and 0.67 , and with \% agreements $87.3-89.1 \%$ and 83.6, respectively. In the VP distribution analysis, intra- and inter-observer agreement was also "substantial" with kappa values $0.64-0.65$ and 0.70 , and with \% agreements $74.5-76.4$ and $80.0 \%$, respectively.

\section{Prevalence of various VP types and distribution}

VP shape type analysis revealed that among the total number of VP-positive discs, the island type was the most common (119 discs [53\%]), followed by linear (61 discs [27\%]) and spot (46 discs [20\%]). There was no significant difference in the proportion of each VP shape between males (Spot: 18\%; Linear: 26\%; Island 56\%) and females (Spot: 23\%; Linear: 28\%; Island 49\%) $(P=0.47)$ (Fig. 4a). No significant differences in these proportions were identified among all age groups $(P=0.5)$, and the island type had the highest proportion in all age groups more than 51 years-old (Fig. 4b).

The analysis of VP distribution revealed that A- $\mathrm{N}$ was the most common area group (95 discs [42\%]), followed by $\mathrm{N}$ (71 discs [32\%]), N-P (37 discs [17\%]) and A-N-P (23 discs [9\%]) area groups. There were no significant differences in the proportion of each VP distribution between males (A-N: 39\%; N: 32\%; N-P: 16\%; A-N-P: $13 \%$ ) and females (A-N: 46\%; N: 30\%; N-P: $17 \%$; A-N-P: $6 \%)(P=0.23)$ (Fig. 5a). No significant differences in these proportions were found in all age groups $(P=0.52)$ (Fig. $5 b)$.
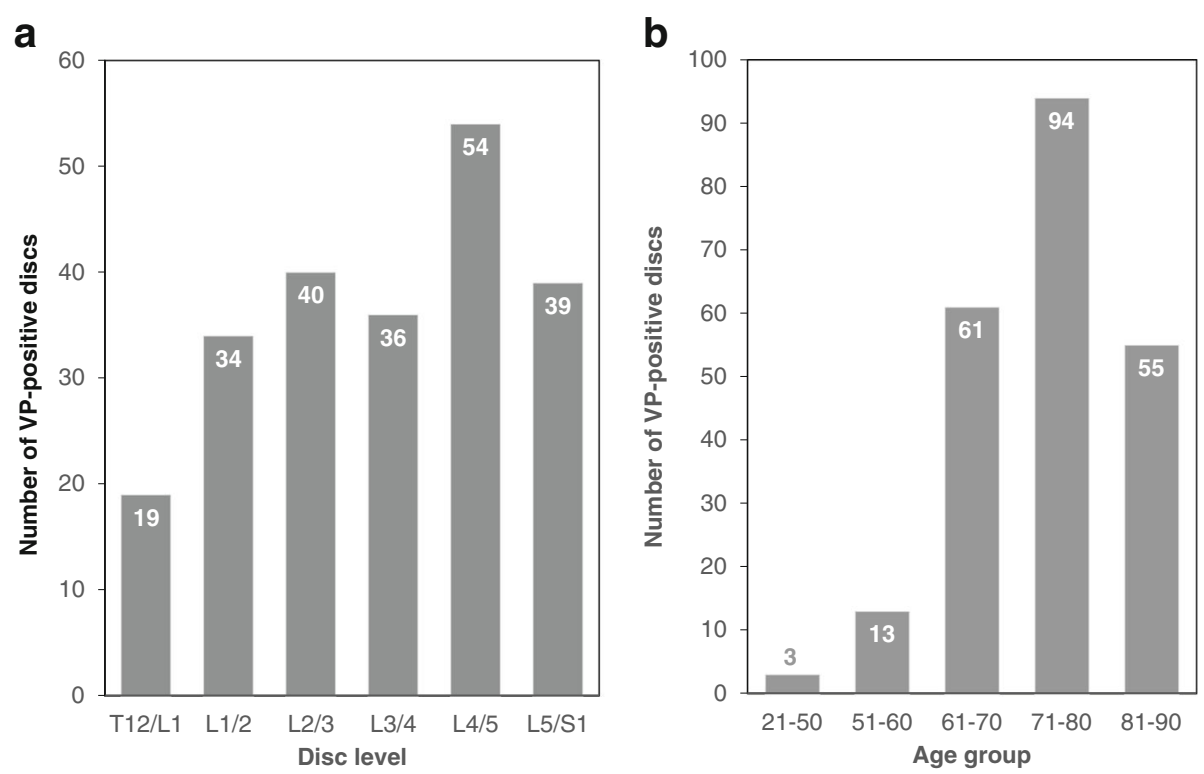

Fig. 3 Number of vacuum phenomena (VP)-positive discs at different intervertebral disc levels (a) and by different age groups (b) 

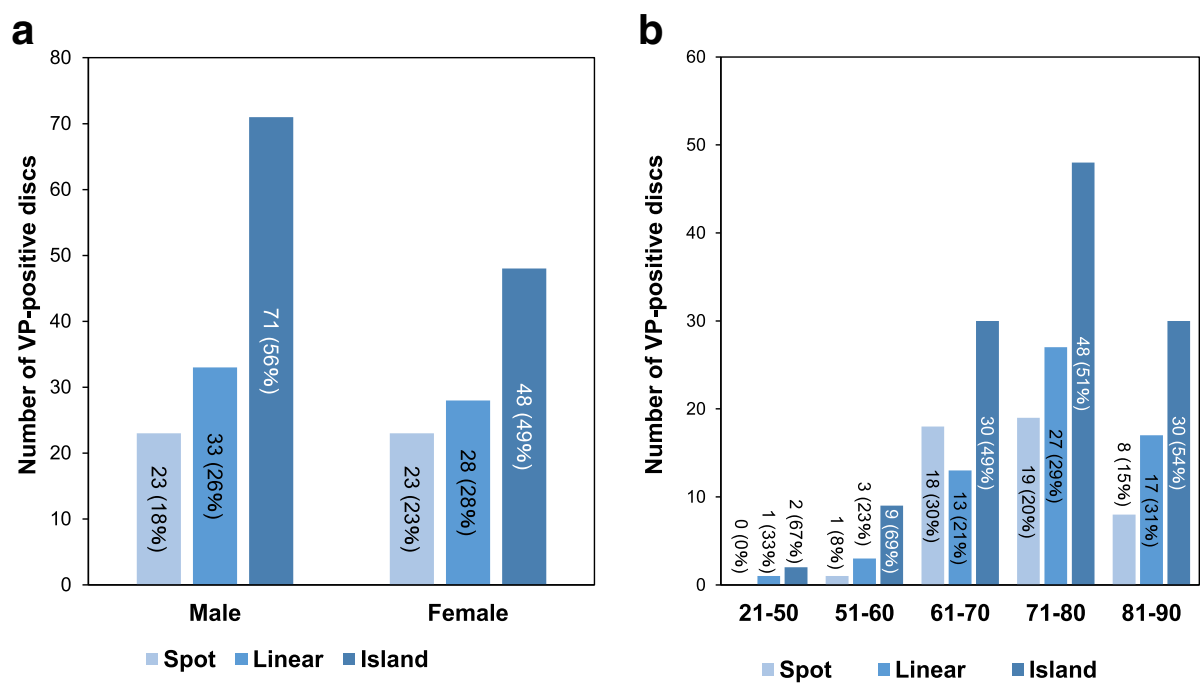

Fig. 4 Characteristics of intradiscal vacuum phenomena (VPs) in shape classification. a Number of vacuum phenomena (VPs) positive-discs by shape classification in males and females. b Number of VP-positive discs by age group by VP shape classification. The counts of VP-positive discs are written in the graph. Percentages in parentheses indicate the proportion of VP-positive discs of each rupture shape compared with the total number of VP-positive discs by gender (a) and by age group (b)

\section{Association between the shape and distribution of VPs}

A Pearson's chi-square test revealed a significant association between the shape and distribution of VPs $(P<0.0001)$.

Spot type VPs tended to be distributed in the A-N (\% of total number of VP-positive discs: $9.7 \%)$ and $\mathrm{N}(8.4 \%)$ areas with high frequency; however no significant differences were identified in this distribution trend (Fig. 6). Linear type VPs were most highly distributed in the $\mathrm{N}$
(15.0\%) area with statistical significance $(P<0.0001)$, followed by A-N (8.8\%), then N-P (3.1\%) areas (Fig. 6). No linear type VPs were found in the A-N-P area $(P<0.0001)$. Island type VPs were most highly distributed in the A-N (23.5\%) area, however no statistical difference was identified $(P=0.8)$. There was a significantly lower frequency of the island type located in the $\mathrm{N}$ area $(8.0 \%, \mathrm{P}<0.0001)$, and a significantly higher frequency in the A-N-P area $(10.2 \%, P<0.004)$.
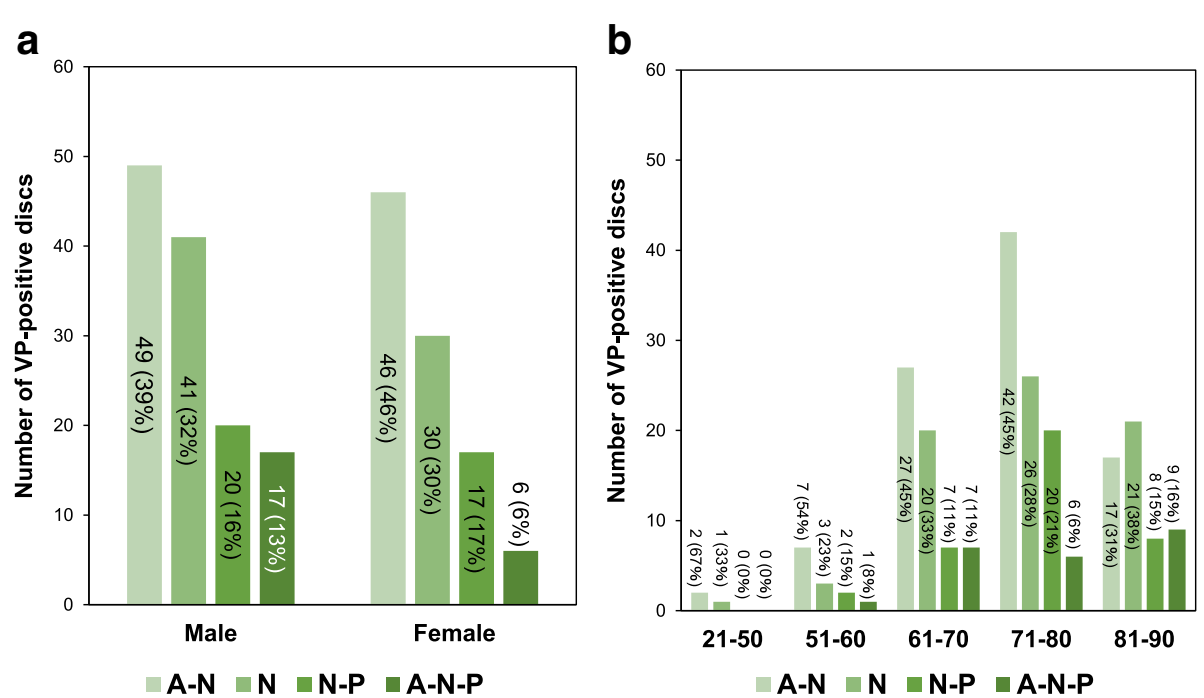

Fig. 5 Characteristics of intradiscal vacuum phenomena by distribution. a Number of vacuum phenomenon (VP)-positive discs in males and females. b Number of vacuum phenomena (VPs) by age group in VPs distribution. The counts of VP-positive discs are written in the graph. Percentages in parentheses indicate the proportion of VP-positive discs of each rupture shape compared with the total number of VP-positive discs by gender (a) and by age group (b). VP: vacuum phenomenon; VP-: non-ruptured group; Nucleus pulposus: N; anterior annulus fibrosus: A; and posterior annulus fibrosus: $\mathrm{P}$ 


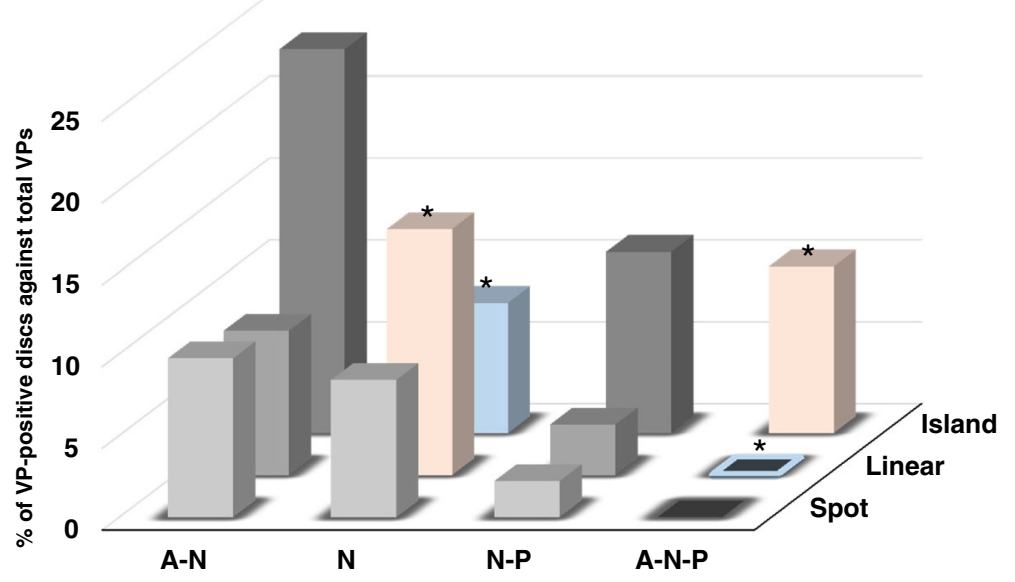

Fig. 6 Association between vacuum phenomenon shape type and distribution. The percentage of vacuum phenomenon (VP)-positive discs of the total number of VP-positive discs in each combination of shape and distribution classification is presented. Nucleus pulposus: $\mathrm{N}$; anterior annulus fibrosus: A; and posterior annulus fibrosus: $P .{ }^{*} P<0.004$ (by Bonferroni correction)

\section{Association of VP type and distribution with disc height} In the VP shape type analysis (Fig. 7a), the DHI of the VP-negative (-) group was significantly higher than that of the island type group $(P<0.01)$; however no significant differences were found with linear and spot types. Among the VP-positive (+) discs, the DHI tended to be highest in spot type VPs, lower in linear VPs, and lowest in island VPs. The DHI in the island type groups was significantly lower than that of the other groups $(P<0.01)$ (Fig. 7a).

In the VP distribution study (Fig. 7b), the DHI in A-N and A-N-P area groups was significantly lower than that of the VP $(-)$ group $(P<0.01$, respectively; Fig. $7 \mathrm{~b})$. In addition, the DHI in A-N and A-N-P area groups was significantly lower than that of the $\mathrm{N}$ distribution $(P<0.01)$.
Association of VP shape type and distribution with disc degeneration

In the VP shape type analysis (Table 2A), the Fisher's exact test showed a significant association between VP shapes and MRI grades of disc degeneration $(P<0.0001)$. The results of the post-hoc test showed that VP (-) discs had a significantly higher proportion of discs with MRI grade 2 (percentages of the raw marginal total: $20.6 \%$ ) and grade $3(28.8 \%)$, but significantly lower with grade 5 (10.5\%) (Table 2A, Fig. 8a). The proportion of spot type discs was highest in MRI grade 4 (53.6\%); however those discs showed no significant association with MRI grading (Table 2A, Fig. 8a). In the linear type, the proportion of discs with MRI grade $5(44.4 \%)$ was highest and significantly higher than other MRI grades $(P<0.0001)$.
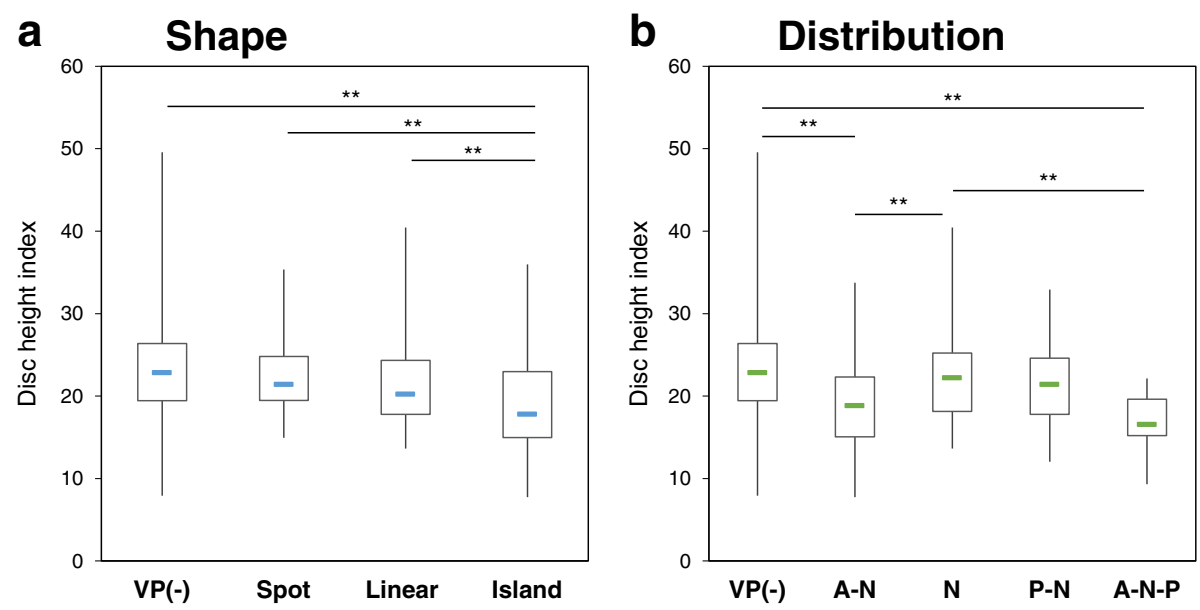

Fig. 7 Association of disc height with shape type of vacuum phenomenon. a Shape type analysis. The disc height index (DHI) in the island type group was significantly lower than that of the other groups. ${ }^{*} P<0.01$. b Distribution analysis. The DHI tended to be lower in the areas including the anterior $A F .{ }^{*} P<0.01$. VP: vacuum phenomenon; VP-: non-ruptured group; Nucleus pulposus: $N$; anterior annulus fibrosus: $A$; and posterior annulus fibrosus: $P$ 
Table 2 Association between intradiscal vacuum phenomena (VPs) and disc degeneration

\begin{tabular}{|c|c|c|c|c|c|c|c|}
\hline \multirow[t]{2}{*}{ A: Shape } & & \multicolumn{5}{|c|}{ MRI Pfirrmann's classification of disc degeneration } & \multirow[t]{2}{*}{ Total } \\
\hline & & । & $\|$ & III & IV & V & \\
\hline \multirow[t]{3}{*}{$\mathrm{VP}(-)$} & $\begin{array}{l}\text { Count } \\
\text { (\% raw) }\end{array}$ & $\begin{array}{l}8 \\
(3.0 \%)\end{array}$ & $\begin{array}{l}55^{*} \\
(20.6 \%)\end{array}$ & $\begin{array}{l}77^{*} \\
(28.8 \%)\end{array}$ & $\begin{array}{l}99 \\
(37.1 \%)\end{array}$ & $\begin{array}{l}28 * \\
(10.5 \%)\end{array}$ & \multirow[t]{3}{*}{267} \\
\hline & Exp. Count & 4.8 & 34.5 & 59.3 & 102.3 & 66.0 & \\
\hline & $\begin{array}{l}\text { Corrected } \\
P \text {-value }\end{array}$ & 0.02 & $<0.0001$ & $<0.0001$ & 0.51 & $<0.0001$ & \\
\hline \multirow[t]{3}{*}{ Spot } & Count(\% raw) & $\begin{array}{l}0 \\
(0 \%)\end{array}$ & $\begin{array}{l}1 \\
(2.6 \%)\end{array}$ & $\begin{array}{l}13 \\
(34.2 \%)\end{array}$ & $\begin{array}{l}20 \\
(52.6 \%)\end{array}$ & $\begin{array}{l}4 \\
(10.5 \%)\end{array}$ & \multirow[t]{3}{*}{38} \\
\hline & Exp. Count & 0.7 & 4.9 & 8.4 & 14.6 & 9.4 & \\
\hline & $\begin{array}{l}\text { Corrected } \\
P \text {-value }\end{array}$ & 0.38 & 0.05 & 0.06 & 0.06 & 0.03 & \\
\hline \multirow[t]{3}{*}{ Linear } & $\begin{array}{l}\text { Count } \\
\text { (\% raw) }\end{array}$ & $\begin{array}{l}0 \\
(0 \%)\end{array}$ & $\begin{array}{l}1 \\
(2.2 \%)\end{array}$ & $\begin{array}{l}8 \\
(17.8 \%)\end{array}$ & $\begin{array}{l}16 \\
(35.6 \%)\end{array}$ & $\begin{array}{l}20 * \\
(44.4 \%)\end{array}$ & \multirow[t]{3}{*}{45} \\
\hline & Exp. Count & 0.8 & 5.8 & 10.0 & 17.2 & 11.1 & \\
\hline & $\begin{array}{l}\text { Count } \\
\text { (\% raw) }\end{array}$ & 0.03 & 0.02 & 0.45 & 0.69 & 0.0012 & \\
\hline \multirow[t]{3}{*}{ Island } & $\begin{array}{l}\text { Count } \\
\text { (\% raw) }\end{array}$ & $\begin{array}{l}0 \\
(0 \%)\end{array}$ & $\begin{array}{l}0 * \\
(0 \%)\end{array}$ & $\begin{array}{l}0 * \\
(0 \%)\end{array}$ & $\begin{array}{l}34 \\
(37.4 \%)\end{array}$ & $\begin{array}{l}57 * \\
(62.6 \%)\end{array}$ & \multirow[t]{3}{*}{91} \\
\hline & Exp. Count & 1.7 & 11.8 & 20.2 & 34.9 & 22.5 & \\
\hline & $\begin{array}{l}\text { Corrected } \\
\text { P-value }\end{array}$ & 0.15 & $<0.0001$ & $<0.0001$ & 0.83 & $<0.0001$ & \\
\hline \multirow[t]{2}{*}{ B: Distribution } & & \multicolumn{5}{|c|}{ MRI Pfirrmann's classification of disc degeneration } & \multirow[t]{2}{*}{ Total } \\
\hline & & । & $\|$ & III & IV & V & \\
\hline \multirow[t]{3}{*}{$\mathrm{VP}(-)$} & $\begin{array}{l}\text { Count } \\
\text { (\% raw) }\end{array}$ & $\begin{array}{l}8 \\
(3.0 \%)\end{array}$ & $\begin{array}{l}55^{\#} \\
(20.6 \%)\end{array}$ & $\begin{array}{l}77^{\#} \\
(28.8 \%)\end{array}$ & $\begin{array}{l}99 \\
(37.1 \%)\end{array}$ & $\begin{array}{l}28{ }^{\#} \\
(10.5 \%)\end{array}$ & \multirow[t]{3}{*}{267} \\
\hline & Exp. Count & 4.8 & 34.5 & 59.3 & 102.3 & 66.0 & \\
\hline & $\begin{array}{l}\text { Corrected } \\
P \text {-value }\end{array}$ & 0.02 & $<0.0001$ & $<0.0001$ & 0.51 & $<0.0001$ & \\
\hline \multirow[t]{3}{*}{$A-N$} & $\begin{array}{l}\text { Count } \\
\text { (\% raw) }\end{array}$ & $\begin{array}{l}0 \\
(0 \%)\end{array}$ & $\begin{array}{l}2 \\
(2.7 \%)\end{array}$ & $\begin{array}{l}10 \\
(13.5 \%)\end{array}$ & $\begin{array}{l}26 \\
(35.1 \%)\end{array}$ & $\begin{array}{l}36{ }^{\#} \\
(48.6 \%)\end{array}$ & \multirow[t]{3}{*}{74} \\
\hline & Exp. Count & 1.3 & 9.6 & 16.4 & 28.4 & 18.3 & \\
\hline & $\begin{array}{l}\text { Corrected } \\
P \text {-value }\end{array}$ & 0.20 & 0.004 & 0.45 & 0.53 & $<0.0001$ & \\
\hline \multirow[t]{3}{*}{ N } & $\begin{array}{l}\text { Count } \\
\text { (\% raw) }\end{array}$ & $\begin{array}{l}0 \\
(0 \%)\end{array}$ & $\begin{array}{l}0 \\
(0 \%)\end{array}$ & $\begin{array}{l}9 \\
(16.4 \%)\end{array}$ & $\begin{array}{l}28 \\
(50.9 \%)\end{array}$ & $\begin{array}{l}18 \\
(32.7 \%)\end{array}$ & \multirow[t]{3}{*}{55} \\
\hline & Exp. Count & 1.0 & 7.1 & 12.2 & 21.1 & 13.6 & \\
\hline & $\begin{array}{l}\text { Corrected } \\
P \text {-value }\end{array}$ & 0.28 & 0.0023 & 0.26 & 0.04 & 0.14 & \\
\hline \multirow[t]{3}{*}{$N-P$} & $\begin{array}{l}\text { Count } \\
\text { (\% raw) }\end{array}$ & $\begin{array}{l}0 \\
(0 \%)\end{array}$ & $\begin{array}{l}0 \\
(0 \%)\end{array}$ & $\begin{array}{l}2 \\
(7.1 \%)\end{array}$ & $\begin{array}{l}11 \\
(39.3 \%)\end{array}$ & $\begin{array}{l}15^{\#} \\
(53.6 \%)\end{array}$ & \multirow[t]{3}{*}{28} \\
\hline & Exp. Count & 0.5 & 3.6 & 6.2 & 10.7 & 6.9 & \\
\hline & $\begin{array}{l}\text { Corrected } \\
P \text {-value }\end{array}$ & 0.46 & 0.004 & 0.05 & 0.91 & 0.00025 & \\
\hline \multirow[t]{3}{*}{ A-N-P } & $\begin{array}{l}\text { Count } \\
\text { (\% raw) }\end{array}$ & $\begin{array}{l}0 \\
(0 \%)\end{array}$ & $\begin{array}{l}0 \\
(0 \%)\end{array}$ & $\begin{array}{l}0 \\
(0 \%)\end{array}$ & $\begin{array}{l}5 \\
(29.4 \%)\end{array}$ & $\begin{array}{l}12{ }^{\#} \\
(70.6 \%)\end{array}$ & \multirow[t]{3}{*}{17} \\
\hline & Exp. Count & 0.3 & 2.2 & 3.8 & 6.5 & 4.2 & \\
\hline & $\begin{array}{l}\text { Corrected } \\
P \text {-value }\end{array}$ & 0.2 & 0.004 & 0.05 & 0.53 & $<0.0001$ & \\
\hline
\end{tabular}

The results of a contingency-table test are presented. A: VP shape analysis. B: VP distribution analysis. Percentages of the raw marginal total (\% raw) are in parentheses. Exp. Count: expected count; VP (-): non-ruptured group; Nucleus pulposus: N; anterior annulus fibrosus: A; and posterior annulus fibrosus: P. *P<0.0025, ${ }^{\#} P<0.002$ (by Bonferroni correction). The cells with counts above or below the expected count with statistical significance are shown in bold 


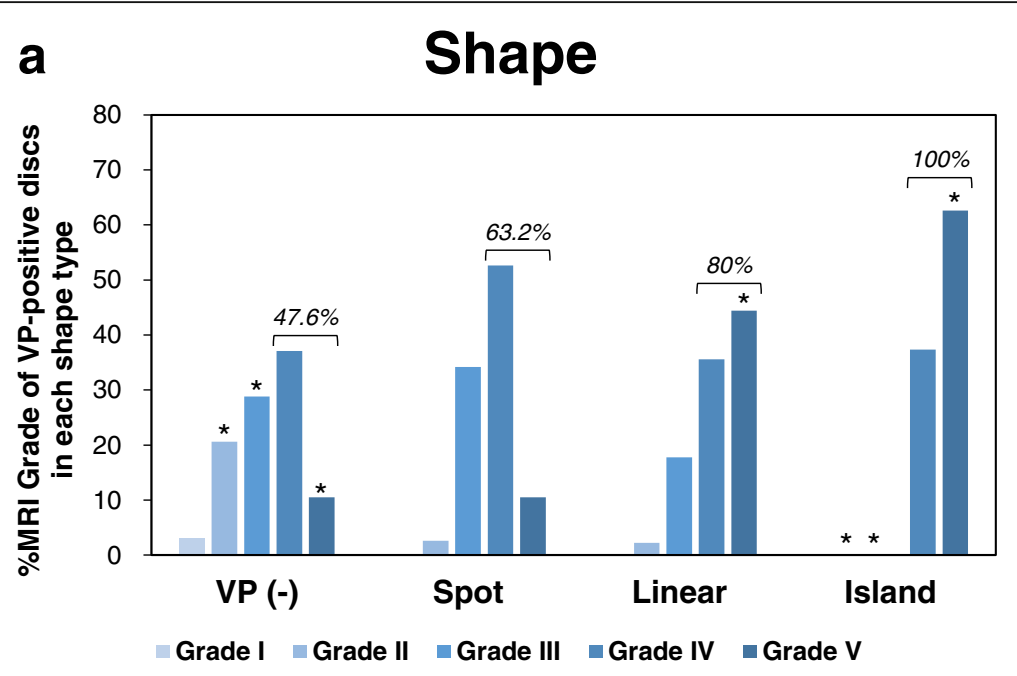

b Distribution

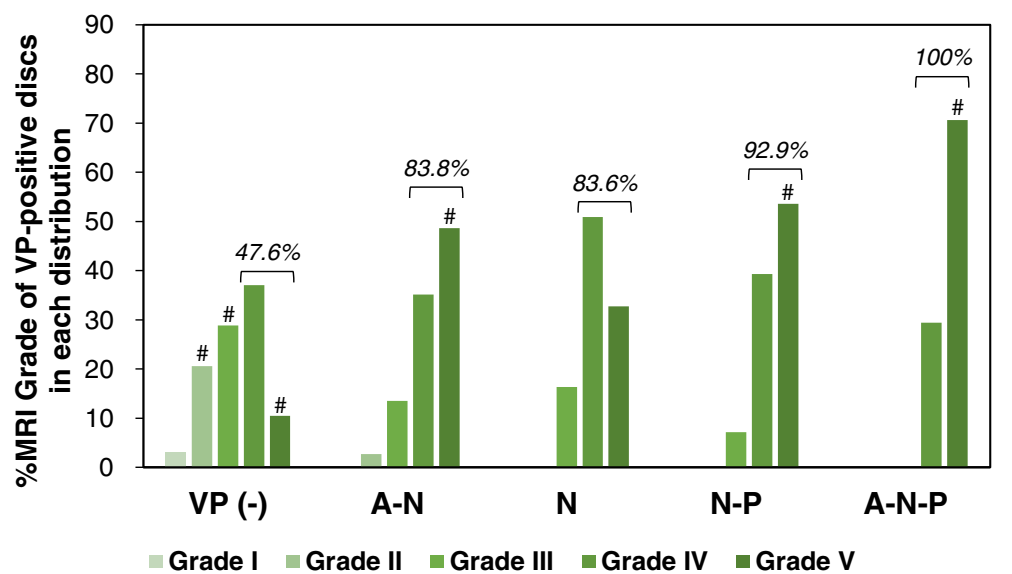

Fig. 8 Percentage of MRI grade of disc degeneration in vacuum phenomenon shape type and distribution analyses. The percentage of MRI grade (Pfirrmann's classification [10]) of disc degeneration in vacuum phenomenon (VP) shape type (a) and distribution (b) analyses. ${ }^{*} P<0.0025$, ${ }^{*} P<0.002$ (by Bonferroni correction). The percentage of advanced degenerative stage discs (Pfirrmann grades IV and V) of each group is indicated by a bracket

Island type discs had a significantly lower proportion of discs with MRI grade $2(0 \%)$ and grade $3(0 \%)$, but significantly higher with MRI grade $5(62.6 \%)(P<0.0001$, respectively) (Table 2A, Fig. 8a).

The distribution of intradiscal VPs was also significantly associated with MRI grade (Fisher's exact test, $P<0.0001)$ (Table 2B). The post-hoc test revealed that the discs with A-N, N-P and A-N-P distribution had the highest and significantly higher proportion of discs with MRI grade 5 (A-N: $48.6 \%, P<0.0001$; N-P: $53.6 \%, P<0.002$; A-N-P: $70.6 \%, P<0.0001)$ than those with other MRI grades, respectively (Table 2B, Fig. $8 \mathrm{~b}$ ). Discs with $\mathrm{N}$ distribution were most frequently classified as MRI grade 4 (50.9\%); however those discs showed no significant effect on the proportion of discs with different MRI grades (Table 2B, Fig. 8b).
Of all the discs analyzed by MRI (441 discs), 63.0\% (278 discs) were in the advanced degenerative stage (Pfirrmann grades IV and V). In the VP shape type analysis, the percentage of discs with advanced stage of degeneration was highest in the island type (100\%) followed by linear (80\%) and spot (63.2\%) types (Fig. 8a). In the VP distribution analysis, the discs with advanced stage of degeneration were most frequently distributed in the A-N-P (100\%) area, followed by N-P (92.9\%), A-N (83.8\%) and $\mathrm{N}(83.6 \%)$ areas (Fig. 8b).

\section{Association of VP type and distribution with lumbar spinal stenosis}

The Fisher's exact test showed a significant association between VP shape type and MRI grade of canal stenosis $(P<0.0001)$ (Table 3A). VP $(-)$ discs had a significantly 
Table 3 Association between intradiscal vacuum phenomena (VPs) and lumbar spinal stenosis

\begin{tabular}{|c|c|c|c|c|c|c|}
\hline \multirow[t]{2}{*}{ A: Shape } & & \multicolumn{4}{|c|}{ MRI classification of lumbar spinal stenosis } & \multirow[t]{2}{*}{ Total } \\
\hline & & A & B & C & $\mathrm{D}$ & \\
\hline \multirow[t]{3}{*}{$\mathrm{VP}(-)$} & $\begin{array}{l}\text { Count } \\
\text { (\% raw) }\end{array}$ & $\begin{array}{l}171 * \\
(81.8 \%)\end{array}$ & $\begin{array}{l}9 \\
(4.3 \%)\end{array}$ & $\begin{array}{l}22 \\
(10.5 \%)\end{array}$ & $\begin{array}{l}7 * \\
(3.3 \%)\end{array}$ & \multirow[t]{3}{*}{209} \\
\hline & Exp. Count & 147.5 & 13.1 & 31.3 & 17.1 & \\
\hline & $\begin{array}{l}\text { Corrected } \\
P \text {-value }\end{array}$ & $<0.0001$ & 0.07 & 0.006 & $<0.0001$ & \\
\hline \multirow[t]{3}{*}{ Spot } & $\begin{array}{l}\text { Count } \\
\text { (\% raw) }\end{array}$ & $\begin{array}{l}21 \\
(61.8 \%)\end{array}$ & $\begin{array}{l}3 \\
(8.8 \%)\end{array}$ & $\begin{array}{l}7 \\
(20.6 \%)\end{array}$ & $\begin{array}{l}3 \\
(8.8 \%)\end{array}$ & \multirow[t]{3}{*}{34} \\
\hline & Exp. Count & 24.0 & 2.1 & 5.1 & 2.8 & \\
\hline & $\begin{array}{l}\text { Corrected } \\
P \text {-value }\end{array}$ & 0.23 & 0.51 & 0.34 & 0.89 & \\
\hline \multirow[t]{3}{*}{ Linear } & $\begin{array}{l}\text { Count } \\
\text { (\% raw) }\end{array}$ & $\begin{array}{l}21 \\
(55.3 \%)\end{array}$ & $\begin{array}{l}4 \\
(10.5 \%)\end{array}$ & $\begin{array}{l}5 \\
(13.2 \%)\end{array}$ & $\begin{array}{l}8^{*} \\
(21.1 \%)\end{array}$ & \multirow[t]{3}{*}{38} \\
\hline & Exp. Count & 26.8 & 2.4 & 5.7 & 3.1 & \\
\hline & $\begin{array}{l}\text { Corrected } \\
P \text {-value }\end{array}$ & 0.03 & 0.35 & 0.74 & 0.0022 & \\
\hline \multirow[t]{3}{*}{ Island } & $\begin{array}{l}\text { Count } \\
\text { (\% raw) }\end{array}$ & $\begin{array}{l}46 * \\
(53.5 \%)\end{array}$ & $\begin{array}{l}7 \\
(8.1 \%)\end{array}$ & $\begin{array}{l}21 \\
(24.4 \%)\end{array}$ & $\begin{array}{l}12 \\
(14.0 \%)\end{array}$ & \multirow[t]{3}{*}{86} \\
\hline & Exp. Count & 60.7 & 5.4 & 12.9 & 7.0 & \\
\hline & $\begin{array}{l}\text { Corrected } \\
P \text {-value }\end{array}$ & 0.0001 & 0.41 & 0.005 & 0.025 & \\
\hline \multirow[t]{2}{*}{ B: Distribution } & & \multicolumn{4}{|c|}{ MRI classification of lumbar spinal stenosis } & Total \\
\hline & & A & B & C & $D$ & \\
\hline \multirow[t]{3}{*}{ VP (-) } & $\begin{array}{l}\text { Count } \\
\text { (\% raw) }\end{array}$ & $\begin{array}{l}171^{\#} \\
(81.8 \%)\end{array}$ & $\begin{array}{l}9 \\
(4.3 \%)\end{array}$ & $\begin{array}{l}22 \\
(10.5 \%)\end{array}$ & $\begin{array}{l}7^{\#} \\
(3.3 \%)\end{array}$ & \multirow[t]{3}{*}{209} \\
\hline & Exp. Count & 147.5 & 13.1 & 31.3 & 17.1 & \\
\hline & $\begin{array}{l}\text { Corrected } \\
P \text {-value }\end{array}$ & $<0.0001$ & 0.07 & 0.006 & $<0.0001$ & \\
\hline \multirow[t]{3}{*}{$\mathrm{A}-\mathrm{N}$} & $\begin{array}{l}\text { Count } \\
\text { (\% raw) }\end{array}$ & $\begin{array}{l}41 \\
(63.1 \%)\end{array}$ & $\begin{array}{l}5 \\
(7.7 \%)\end{array}$ & $\begin{array}{l}9 \\
(13.8 \%)\end{array}$ & $\begin{array}{l}10 \\
(15.4 \%)\end{array}$ & \multirow[t]{3}{*}{65} \\
\hline & Exp. Count & 45.9 & 4.1 & 9.7 & 5.3 & \\
\hline & $\begin{array}{l}\text { Corrected } \\
P \text {-value }\end{array}$ & 0.14 & 0.60 & 0.77 & 0.02 & \\
\hline \multirow[t]{3}{*}{ N } & $\begin{array}{l}\text { Count } \\
\text { (\% raw) }\end{array}$ & $\begin{array}{l}26 \\
(53.1 \%)\end{array}$ & $\begin{array}{l}7 \\
(14.3 \%)\end{array}$ & $\begin{array}{l}9 \\
(18.4 \%)\end{array}$ & $\begin{array}{l}7 \\
(14.3 \%)\end{array}$ & \multirow[t]{3}{*}{49} \\
\hline & Exp. Count & 34.6 & 3.1 & 7.3 & 4.0 & \\
\hline & $\begin{array}{l}\text { Corrected } \\
P \text {-value }\end{array}$ & 0.0039 & 0.013 & 0.48 & 0.09 & \\
\hline \multirow[t]{3}{*}{$N-P$} & $\begin{array}{l}\text { Count } \\
\text { (\% raw) }\end{array}$ & $\begin{array}{l}12^{\#} \\
(44.4 \%)\end{array}$ & $\begin{array}{l}2 \\
(7.4 \%)\end{array}$ & $\begin{array}{l}7 \\
(25.9 \%)\end{array}$ & $\begin{array}{l}6 \\
(22.2 \%)\end{array}$ & \multirow[t]{3}{*}{27} \\
\hline & Exp. Count & 19.1 & 1.7 & 4.0 & 2.2 & \\
\hline & $\begin{array}{l}\text { Corrected } \\
P \text {-value }\end{array}$ & 0.0019 & 0.07 & 0.005 & 0.0001 & \\
\hline \multirow[t]{3}{*}{ A-N-P } & $\begin{array}{l}\text { Count } \\
\text { (\% raw) }\end{array}$ & $\begin{array}{l}9 \\
(52.9 \%)\end{array}$ & $\begin{array}{l}0 \\
(0 \%)\end{array}$ & $\begin{array}{l}8^{\#} \\
(47.1 \%)\end{array}$ & $\begin{array}{l}0 \\
(0 \%)\end{array}$ & \multirow[t]{3}{*}{17} \\
\hline & Exp. Count & 12.0 & 1.1 & 2.5 & 1.4 & \\
\hline & $\begin{array}{l}\text { Corrected } \\
P \text {-value }\end{array}$ & 0.1 & 0.27 & 0.00015 & 0.21 & \\
\hline
\end{tabular}

The results of a contingency-table test are presented. A: VP shape analysis. B: VP distribution analysis. Percentages of the raw marginal total (\% raw) are in parentheses. Exp. Count: expected count; VP (-): non-ruptured group; Nucleus pulposus: $N$; anterior annulus fibrosus: A; and posterior annulus fibrosus: $P$. ${ }^{*} P<0.0025$, ${ }^{\#} P<0.002$ (by Bonferroni correction). The cells with counts above or below the expected count with statistical significance are shown in bold 
higher proportion of grade A stenosis (percentages of the raw marginal total: $81.8 \%$ ), and significantly lower proportion of grade D stenosis (3.3\%) at corresponding disc levels (Table 3A, Fig. 9a). Discs with a linear type VP had a significantly higher proportion of grade D stenosis (21.1\%), and discs with an island type VP had a significantly lower proportion of grade A stenosis (53.5\%) at corresponding disc levels (Table 3A, Fig. 9a).

The distribution of VPs also had a significant association with the MRI grade of canal stenosis (Fisher's exact test, $P<0.0001$ ) (Table $3 \mathrm{~B}$ ). The discs with N-P distributions had a significantly lower proportion of MRI grade A canal stenosis (44.4\%), and the discs with A-N-P distributions had a significantly higher proportion with MRI grade C canal stenosis (47.1\%) at the corresponding disc levels (Table 3B, Fig. 9b). On the other hand, the discs with A-N and $\mathrm{N}$ distributions had no significant association with MRI grade of canal stenosis at corresponding disc levels (Table 3B, Fig. 9b).

The percentage of VP-positive discs with severe stenosis (grades C and D) at the corresponding disc level in all analyzed discs was $23.1 \%$. The percentage of discs with severe stenosis in each shape type was highest in the island type (38.4\%) followed by linear (34.2\%) and spot (29.4\%) types (Fig. 9a). The VP in discs with severe stenosis at the corresponding disc level was most frequently distributed to the N-P (48.1\%) area, followed by A-N-P (47.1\%), $\mathrm{N}$ (32.7\%) and A-N (29.2\%) areas (Fig. 9b).

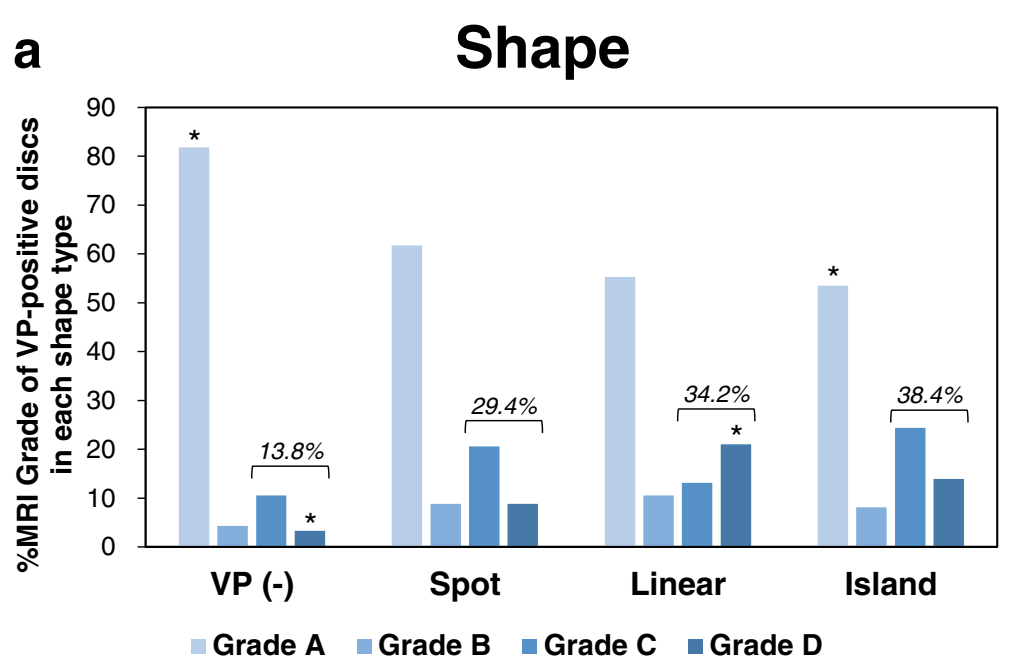

b Distribution

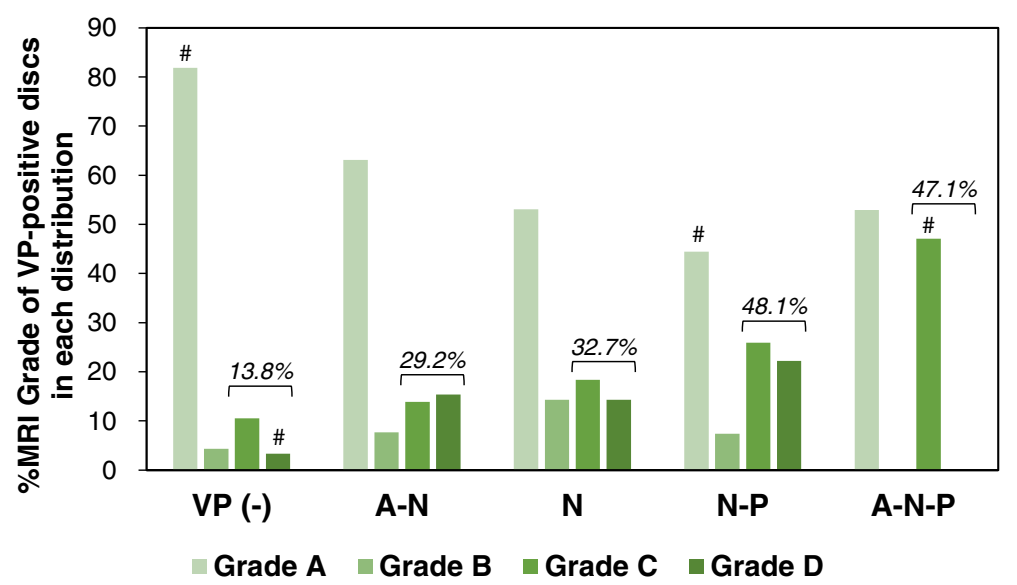

Fig. 9 Percentage of MRI grade of lumbar spinal stenosis in vacuum phenomenon shape type and distribution analyses. The percentage of MRI grade (Schizas's classification [1 1]) of lumbar spinal stenosis in vacuum phenomenon (VP) shape type (a) and distribution (b) analyses. ${ }^{*} P<0.0025$, ${ }^{\#} P<0.002$ (by Bonferroni correction). The percentage of VP-positive discs with severe stenosis (grades $C$ and D) of each group is indicated by a bracket 


\section{Discussion}

To evaluate the morphology of IVD ruptures in the lumbar spine, we performed a cross-sectional retrospective CT study to assess intradiscal VPs of consecutive patients who underwent spinal surgery. The results showed that VPs were found in $38.3 \%$ of the 587 discs analyzed, most prominently at the L4/5 level and highest in the seventy years-old population. The type and distribution of intradiscal VPs were significantly associated with severity of MRI grade of disc degeneration and disc height narrowing. The presence of VPs within the disc also had a significant effect on the lumbar spinal stenosis of corresponding IVDs.

Intradiscal VPs are most commonly seen in patients with disc degeneration, especially in the NP, where dehydration of the disc and enlarging clefts lead to the accumulation of gas [4, 16, 17]. VPs in IVDs were first described by Magnusson in 1937 [18] and are a common finding that can be observed in 1-3\% of healthy adults on spinal radiographs [19-21], but can reach a prevalence of $20 \%$ in elderly patients [4, 22, 23]. Ford and colleagues reported that intradiscal VPs contain 90-92\% nitrogen combined with oxygen, carbon dioxide and traces of other gases [24]. Because nitrogen gas is hard to metabolize within tissues in vivo, it can accumulate within the tissue organization.

With the progression of disc degeneration, the crevices extend peripherally, affecting first the inner fibers and later the outer fibers of the AF. At the same time, gas collections may become more prominent, extending from the interior to the exterior of the affected disc [4]. Therefore, the position and form of intradiscal VPs are considered to indicate the distribution and extent of ruptures within IVD tissues. Gas accumulation in the spinal canal or in disc herniation is reported to be associated with neurologic symptoms, although the clinical significance of intradiscal VPs has been controversial.

In this study, we first classified the morphology of intradiscal VPs, using CT images to evaluate the degree of disc rupture by shape (sagittal-plane) and distribution (axial-plane). Both intra- and inter-observer agreements of this two-part classification system are "substantial" by kappa statistics, and showed higher \% agreements, suggesting that this classification system would be sufficient to distinguish between the different VP shapes and distributions.

The results of our study showed evidence that the presence of intradiscal VPs has a significant association with the degree of disc degeneration graded by MRI. In addition, the extent of disc ruptures evaluated by the types and distribution of intradiscal VPs also significantly affects the MRI grading of disc degeneration. Discs with linear and island shape VPs had a significantly higher proportion of MRI grade V discs, which indicated the collapse of discs with significant structural changes [10]. In the distribution analysis, except for the $\mathrm{N}$ distribution, all the discs with the VPs that extend from NP into anterior and/or posterior AF (A-N, N-P, A-N-P) had a significantly higher proportion of MRI grade $\mathrm{V}$ discs. These results suggested that intradiscal VPs extending from the $\mathrm{N}$ into AF area are associated with significant structural changes of IVDs.

The results of lumbar radiography also showed that there is a significant trend for disc height to decrease in accordance with the extent of disc rupture evaluated by the type of intradiscal VPs. Taking the distribution of VPs into account, disc height was significantly lower in discs that contained VPs in the area of the anterior AF. In the clinical setting, disc height narrowing is the commonly used radiographic finding indicating disc degeneration; however, according to Pfirrmann's classification [10], this change is recognized as a finding related to an advanced stage (more than grade IV) of disc degeneration with significant structural changes [9].

We also evaluated the association between intradiscal VPs and lumbar spinal stenosis. In this study, we also showed evidence that lumbar spinal stenosis was significantly associated with the presence of VPs at the corresponding IVD. Severe stenosis (grades $\mathrm{C}$ and $\mathrm{D}$ by MRI classification [11]) was most frequently identified in IVDs containing the island type VP, especially those including the posterior AF. Ligamentum flavum thickness, disc protrusion, and spondylolisthesis are major pathogeneses of lumbar spinal stenosis. Intradiscal VPs have been recognized as one of the signs of segmental instability [5, 25-27]. Therefore, the results of our study further support the possibility that the presence of intradiscal VPs would lead to segmental instability, which is responsible for the pathogenesis of lumbar spinal stenosis.

Clinical relevance: Recently, the effects of intradiscal VPs on the clinical (surgical) outcome of lumbar fusion surgery have been reported [5, 27, 28]. Liao et al. [5] reported that intradiscal VPs should be regarded as a sign of intervertebral instability. Hence, lumbar interbody fusion (LIF) surgery with intervertebral cage, but not posterolateral fusion only, should be performed for patients with degenerative lumbar spondylolisthesis containing intradiscal VPs. LIF surgery including lateral and posterior approaches with cages has been reported to be effective for restoration of disc height, lumbar lordosis and also for improving the bone fusion rate in lumbar spondylolisthesis patients with intradiscal VPs $[5,27,28]$. The results of this study also revealed that intradiscal VPs, especially those extending from the $\mathrm{N}$ into the AF region, were associated with structural destruction of IVD tissues, including disc height narrowing. Therefore, our morphological classification of 
VPs might be advantageous in determining the surgical procedure used for treating degenerative lumbar diseases.

Limitations of this study were that most of the subjects were patients who had taken pre-operative CT images for elective spinal surgeries, and that an age-matched general population was not used as a control in this study. Therefore, the percentage of intradiscal VPs in our subjects would be much higher than that within an age-matched general population. This is the first study analyzing the shape type and distribution of intradiscal VPs using CT images to indicate that VPs were frequently distributed in the NP and anterior AF. However, it should be kept in mind that the anterior distribution of VPs would be more enhanced in a CT study using a supine position compared with the exact distribution of disc ruptures evaluated in cadaveric studies $[1,2]$. Another limitation was that the morphological classification of intradiscal VPs was performed using sagittal and axial CT images analyzed separately with different classifications. A three-dimensional analysis of VPs may be needed for more precise evaluations of area, distribution and volume of intradiscal VPs.

Importantly, when the intradiscal VPs were evaluated by MRI T2-wighted images, approximately $10 \%$ of VP-positive discs showed high signal intensity, demonstrating MR imaging findings similar to those of infectious spondylodiscitis $[7,29,30]$. The presence of intradiscal VPs evaluated by $\mathrm{CT}$ images would aid in the exclusion diagnosis of infectious spondylodiscitis [31].

\section{Conclusions}

This study describes the assessment of IVD ruptures by the presence of intradiscal VPs using CT-imaging. This two-part classification can comprehensively present the shape and axial distribution of VPs within IVDs, with intra- and inter-observer reliability sufficient to classify different rupture shapes and distributions. This study also showed evidence that the presence of intradiscal VPs is associated with MRI-grading of disc degeneration and radiographic disc height narrowing. Therefore, the presence of intradiscal VPs represents one of the signs of disc ruptures with a significant structural change. This systematic analysis of intradiscal VPs also revealed that the shape and distribution of VPs were significantly associated with the MRI-grading of lumbar canal stenosis at the corresponding disc level. To further evaluate the clinical relevance of intradiscal VPs, it would be important in future studies to examine the association between segmental intervertebral instability and/or clinical symptoms using this CT-based analytical system.

\section{Abbreviations}

AF: annulus fibrosus; CT: computed tomography; DHI: disc height index; IVD: intervertebral disc; LSS: lumbar spinal stenosis; MDCT: multi-detector computed tomography; MRI: magnetic resonance imaging; NP: nucleus pulposus; VP: vacuum phenomenon

\section{Availability of data and materials}

The datasets used and/or analyzed during the current study are available from the corresponding author on reasonable request.

\section{Authors' contributions}

KMu performed data acquisition and statistical analysis and drafted the manuscript. KA helped to perform data acquisition and statistical analyses and drafted the manuscript, conceived of this study, and made substantial contributions to the study design. NT and KMa performed statistical analysis and revised the manuscript. KC performed data acquisition, and revised the manuscript. AS contributed to the study design and coordination, and revised the manuscript. All authors read and approved the final manuscript.

\section{Ethics approval and consent to participate}

Ethics were approved by the institutional review board of the Mie University Hospital (Tsu, Mie, Japan; IRB reference number: 3110) and Iwasaki Hospital (Tsu, Mie, Japan; IRB reference number: 2015-1201). Written informed consent was obtained from all participants.

\section{Competing interests}

The authors declare that they have no competing interests.

\section{Publisher's Note}

Springer Nature remains neutral with regard to jurisdictional claims in published maps and institutional affiliations.

\section{Author details}

${ }^{1}$ Department of Orthopaedic Surgery, Mie University Graduate School of Medicine, 2-174 Edobashi, Tsu City, Mie 514-8507, Japan. ²Department of Orthopaedic Surgery, University of California, San Diego, 9500 Gilman Dr, La Jolla, CA 92093-0863, USA

Received: 31 January 2018 Accepted: 9 May 2018

Published online: 24 May 2018

\section{References}

1. Osti OL, Vernon-Roberts B, Moore R, Fraser RD. Annular tears and disc degeneration in the lumbar spine. A post-mortem study of 135 discs. J Bone Joint Surg Br. 1992;74(5):678-82.

2. Vernon-Roberts B, Moore RJ, Fraser RD. The natural history of age-related disc degeneration: the pathology and sequelae of tears. Spine (Phila Pa 1976). 2007;32(25):2797-804. https://doi.org/10.1097/BRS. 0b013e31815b64d2.

3. Videman T, Nurminen M. The occurrence of anular tears and their relation to lifetime back pain history: a cadaveric study using barium sulfate discography. Spine (Phila Pa 1976). 2004;29(23):2668-76.

4. Resnick D, Niwayama G, Guerra J Jr, Vint V, Usselman J. Spinal vacuum phenomena: anatomical study and review. Radiology. 1981;139(2):341-8. https://doi.org/10.1148/radiology.139.2.7220878.

5. Liao JC, Lu ML, Niu CC, Chen WJ, Chen LH. Surgical outcomes of degenerative lumbar spondylolisthesis with anterior vacuum disc: can the intervertebral cage overcome intradiscal vacuum phenomenon and enhance posterolateral fusion? J Orthop Sci. 2014;19(6):851-9. https://doi. org/10.1007/s00776-014-0618-Z

6. Kasai $Y$, Takegami $K$, Uchida A. Change of barometric pressure influences low back pain in patients with vacuum phenomenon within lumbar intervertebral disc. J Spinal Disord Tech. 2002;15(4):290-3.

7. Kumar Y, Gupta N, Chhabra A, Fukuda T, Soni N, Hayashi D. Magnetic resonance imaging of bacterial and tuberculous spondylodiscitis with associated complications and non-infectious spinal pathology mimicking infections: a pictorial review. BMC Musculoskelet Disord. 2017;18(1):244. https://doi.org/10.1186/s12891-017-1608-z.

8. Grenier N, Grossman Rl, Schiebler ML, Yeager BA, Goldberg HI, Kressel HY. Degenerative lumbar disk disease: pitfalls and usefulness of MR imaging in detection of vacuum phenomenon. Radiology. 1987;164(3):861-5. https:// doi.org/10.1148/radiology. 164.3.3615888.

9. Akeda K, Yamada T, Inoue N, Nishimura A, Sudo A. Risk factors for lumbar intervertebral disc height narrowing: a population-based longitudinal study in the elderly. BMC Musculoskelet Disord. 2015;16:344. https://doi.org/10. 1186/s12891-015-0798-5. 
10. Pfirrmann CW, Metzdorf A, Zanetti M, Hodler J, Boos N. Magnetic resonance classification of lumbar intervertebral disc degeneration. Spine (Phila Pa 1976). 2001;26(17):1873-8.

11. Schizas C, Theumann N, Burn A, Tansey R, Wardlaw D, Smith FW, et al. Qualitative grading of severity of lumbar spinal stenosis based on the morphology of the dural sac on magnetic resonance images. Spine (Phila Pa 1976). 2010;35(21):1919-24. https://doi.org/10.1097/BRS. Ob013e3181d359bd.

12. Lombard M, Snyder-Duch J, Bracken CC. Content analysis in mass communication research: an assessment and reporting of intercoder reliability. Hum Commun Res. 2002;28:587-604.

13. Landis JR, Koch GG. The measurement of observer agreement for categorical data. Biometrics. 1977;33(1):159-74.

14. Beasley TM, Schumacker RE. Multiple regression approach to analyzing contingency tables: post hoc and planned comparison procedures. J Exp Educ. 1995;64(1):79-93.

15. GARCIA-PEREZ MA, NUNEZ-ANTON V. Cellwise residual analysis in two-way contingency tables. Educ Psychol Meas. 2003;63(5):825-39.

16. Fries JW, Abodeely DA, Vijungco JG, Yeager VL, Gaffey WR. Computed tomography of herniated and extruded nucleus pulposus. J Comput Assist Tomogr. 1982;6(5):874-87.

17. Knutsson F. The vacuum phenomenon in the intervertebral discs. Acta Radiologica [Old Series]. 1942;23(2):173-9. https://doi.org/10.3109/ 00016924209134912

18. Magnusson W. Uber Die Bedingungen Des Hervortretens Der Wirklichen Gelenkspalte Auf Dem Rontgenbilde. Acta Radiol. 1937;18(5):733-41. https:// doi.org/10.3109/00016923709132378.

19. Raines JR. Intervertebral disc fissures (vacuum intervertebral disc). Am J Roentgenol Radium Therapy, Nucl Med. 1953;70(6):964-6.

20. Marr JT. Gas in intervertebral discs. Am J Roentgenol Radium Therapy, Nucl Med. 1953;70(5):804-9.

21. Ford LT, Goodman FG. X-ray studies of the lumbosacral spine. South Med J. 1966:59(10):1123-8.

22. Pierpaolo L, Luciano M, Fabrizio P, Paolo M. Gas-containing lumbar disc herniation. A case report and review of the literature. Spine (Phila Pa 1976). 1993;18(16):2533-6.

23. Gershon-Cohen J, Schraer H, Sklaroff DM, Blumberg N. Dissolution of the intervertebral disk in the aged normal; the phantom nucleus pulposus. Radiology. 1954;62(3):383-7. https://doi.org/10.1148/62.3.383.

24. Ford LT, Gilula LA, Murphy WA, Gado M. Analysis of gas in vacuum lumbar disc. AJR Am J Roentgenol. 1977;128(6):1056-7. https://doi.org/10.2214/ajr. 128.6.1056.

25. Iguchi T, Ozaki T, Chin T, Tsumura N, Kanemura A, Kasahara K, et al. Intimate relationship between instability and degenerative signs at $L 4 / 5$ segment examined by flexion-extension radiography. Eur Spine J. 2011;20(8):1349-54. https:/doi.org/10.1007/s00586-011-1793-7.

26. Hasegawa K, Shimoda H, Kitahara K, Sasaki K, Homma T. What are the reliable radiological indicators of lumbar segmental instability? J Bone Joint Surg Br. 2011;93(5):650-7. https://doi.org/10.1302/0301-620x.93b5.25520.

27. Lin TY, Liao JC, Tsai TT, Lu ML, Niu CC, Chen WJ, et al. The effects of anterior vacuum disc on surgical outcomes of degenerative versus spondylolytic spondylolisthesis: at a minimum two-year follow-up. BMC Musculoskelet Disord. 2014;15:329. https://doi.org/10.1186/1471-2474-15-329.

28. Yen CP, Beckman JM, Vivas AC, Bach K, Uribe JS. Effects of intradiscal vacuum phenomenon on surgical outcome of lateral interbody fusion for degenerative lumbar disease. J Neurosurg Spine. 2017;26(4):419-25. https:// doi.org/10.3171/2016.8.SPINE16421.

29. Schweitzer ME. el-Noueam KI. Vacuum disc: frequency of high signal intensity on T2-weighted MR images. Skelet Radiol. 1998;27(2):83-6.

30. Wang HJ, Chen BB, Yu CW, Hsu CY, Shih TT. Alteration of disc vacuum contents during prolonged supine positioning: evaluation with MR image. Spine (Phila Pa 1976). 2007;32(23):2610-5. https://doi.org/10.1097/BRS. 0b013e318158cb49.

31. Hong SH, Choi JY, Lee JW, Kim NR, Choi JA, Kang HS. MR imaging assessment of the spine: infection or an imitation? Radiographics. 2009;29(2):599-612. https://doi.org/10.1148/rg.292085137.

\section{Ready to submit your research? Choose BMC and benefit from:}

- fast, convenient online submission

- thorough peer review by experienced researchers in your field

- rapid publication on acceptance

- support for research data, including large and complex data types

- gold Open Access which fosters wider collaboration and increased citations

- maximum visibility for your research: over $100 \mathrm{M}$ website views per year

At BMC, research is always in progress.

Learn more biomedcentral.com/submissions 